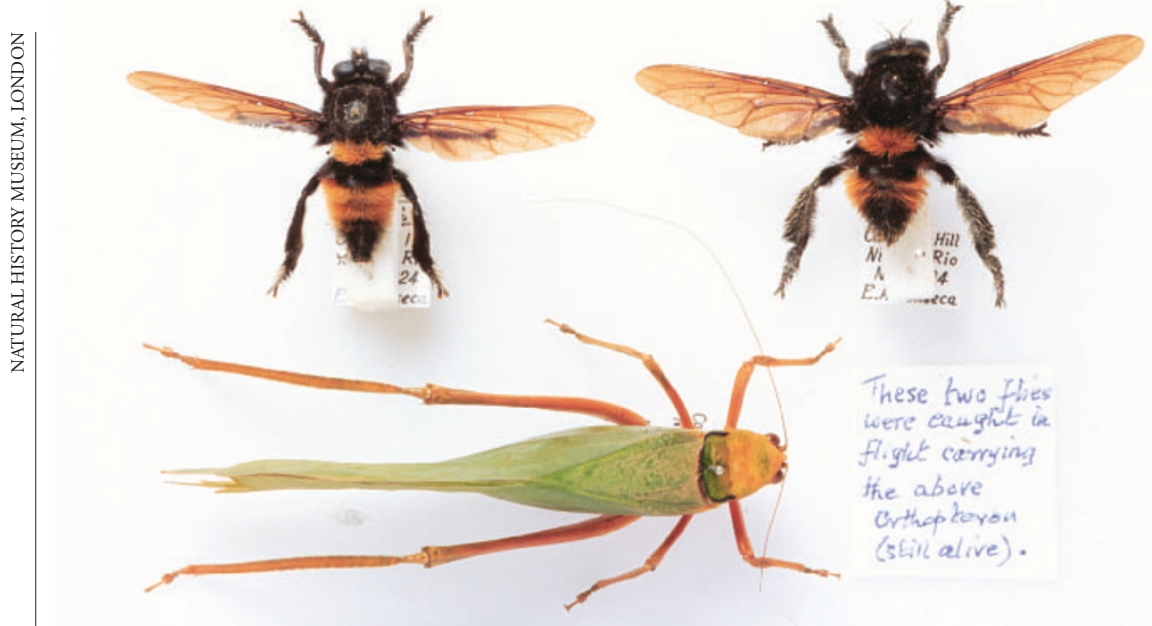

Pin-ups: researchers will soon be able to view 28 million insects through a microscope on the Internet.

\title{
Online access offers fresh scope for bug identification
}

Jim Giles, London

When Michael Schauff's work hits a snag, millions of dollars can be at risk. Insects contaminate thousands of US agricultural imports every year, and Schauff's lab in Beltsville, Maryland, is charged with identifying the immigrant critters. If his team lacks a reference specimen needed for the identification, decisions about whether to quarantine the cargo can become difficult.

Help may soon be at hand. Thanks to a remote-control microscope currently under development, Schauff will soon be able to access another 28 million specimens those in the entomology collection of London's Natural History Museum (NHM). And advocates of the system suggest that it's about far more than customs work - they say the link-up shows how emerging digital technology will transform taxonomy.

When the microscope is installed this May, the US researchers will simply phone through requests for specimens. After a technician in London puts the insect on the microscope, Schauff's team will be able to use the device almost as if they were in the room with it - adjusting magnification, rotating the specimen and taking highresolution images. The system is being developed by two Virginia-based optics companies, Microptics in Ashland and TriTek in Sumerduck.

"We get 5,000 urgent identifications every year and they need a report back the same day,” says Schauff. “That's millions of dollars of stock we're playing with every year."

Quentin Wheeler, head of entomology at the NHM, estimates that the system will cost about US\$135,000 to install at each location. If the technology works, he is keen to expand it to the large insect collections at the natural history museums of Paris and Washington.
Together, the three collections contain more than 100 million specimens covering at least $95 \%$ of all described insect species, he says.

Wheeler adds that the technology will help to promote online collaborations between entomologists and, by archiving pictures taken when examining the specimens, it will eventually create a virtual library of insect specimens.

Adding video conferencing to the software used to control the microscopes would allow experts around the world to discuss the specimens, Wheeler says. And a portable version of the microscope would let entomologists guide the fieldwork of collectors.

But some advocates of a new vision for taxonomy question whether the system is the best way forward. "It is what happens next that will be really exciting," says Charles Godfray, director of the Centre for Population Biology in Ascot, near London, pointing out that in the long term, insect collections can be digitized and made permanently available online.

Several databases of two-dimensional images, such as AntWeb, maintained by the California Academy of Sciences, are already up and running. And Godfray says that three-dimensional images can be created by imaging specimens from several angles and using software to stitch the pictures together.

Wheeler agrees that such a database should be created, but adds that researchers will always need to examine the actual specimens. The intricate structure of many insects' bodies will be difficult to capture using a fixed number of images, he suggests. The size of the collections also makes the creation of thorough databases a very longterm goal. "We've got 28 million specimens here," Wheeler says. "You'll have to give us some time."

\section{Europe's research still lacks competitive edge, says panel}

Quirin Schiermeier, Munich

The European Union's main research programme has met with only "modest" success in its main goal of strengthening Europe's industrial competitiveness. That's the somewhat sobering conclusion of the latest five-year assessment of the Framework funding programme, published last week.

The report's recommendations echo calls that have come from the science community for several years. These include the establishment of a European Research Council (see Nature 425, 440; 2003), the simplification of Framework's notoriously cumbersome funding administration, and the extension of programmes that provide relocation fellowships for young scientists. It also calls for greater participation of small high-tech companies in the next Framework programme, which begins in 2006.

The assessment covers 1999-2003 and was conducted by a 13-strong panel of representatives from both academia and industry, chaired by Erkki Ormala, vicepresident of technology policy at the Finnish IT company Nokia.

"Only a few European universities are recognized as global leaders," laments the report. "This is, at least in part, a result of insufficient resources combined with the fragmented nature of the European research-and-technology development landscape." Opening some national science programmes Europe-wide and improving the coordination of national research activities are suggested as ways to strengthen the overall quality of research in the European Union (EU).

Some of the report's recommendations could well be implemented thanks to an anticipated rise in funds for the Framework programme (see Nature 433, 96; 2005). The new EU research commissioner, Janez Potočnik, hopes to get approval from the European Parliament this summer for a doubling of the EU's four-year research budget to $€ 30$ billion (US $\$ 40$ billion).

Scientists in the new EU member states, where national funding opportunities are few, will be watching to see if the budget rise comes through, and if the report's recommendations are followed. "Any proposal that increases our chance of getting funded is very welcome," says Anna Pytko, vice-director of the Polish National Contact Point for EU research in Warsaw. http://europa.eu.int/comm/research/reports/ 2004/fya_en.html 